\title{
Monte Roraima na América do Sul, Venezuela: Destino Mundial do Turismo de Natureza
}

\author{
Roberto Delfino Maia da Silva ${ }^{i}$ \\ Instituto Nacional de Pesquisas da Amazônia (Brasil) \\ Jefferson da Cruz ${ }^{\text {ii }}$ \\ Universidade Federal do Amazonas (Brasil) \\ Victor Py-Danieliii \\ Instituto Nacional de Pesquisas da Amazônia (Brasil)
}

\begin{abstract}
Resumo: O objetivo do periódico foi analisar e descrever as investigações realizadas na Venezuela na base do Parque Nacional Canaima em (2007) na comunidade indígena de Paraytepuy de Roraima (América do Sul). A metodologia estudou o livro de visitações do Monte Roraima, nos anos de 2002 a 2003, 2005 a 2006 e 2006 a 2007. Neste período foi feita a caminhada ao topo do Monte Roraima na companhia dos guias e carregadores indígenas Pemón Taurepáng. Aproximadamente 3.500 pessoas visitam o Monte Roraima ao ano. Os povos Sul-americanos têm 45,70\% das visitações, Europeus 38,48\%, Norte Americanos 5,12\%, Asiáticos 4,12\% e Oceânicos 1,03\%. O acesso terrestre ao Monte Roraima só é realizado pela Venezuela.
\end{abstract}

Palavras-chave: Monte Roraima; Turismo de Natureza; Povos Indígenas; e Parque Nacional.

Title: Mount Roraima in South America, Venezuela: World Tourism Destination Nature

\begin{abstract}
The objective of paper was to analyze and describe the investigations accomplished in Venezuela in the base of National Park Canaima in (2007) in the indigenous community of Paraytepuy de Roraima (South America). The methodology studies the book of visitations of Roraima Mount, in the years from 2002 to 2003, 2005 to 2006 and 2006 to 2007. In this period it was made the walk to Roraima Mount top in the company of the guides and indigenous loaders Pemón Taurepáng. Approximately 3.500 people visit Roraima Mount a year. The South American peoples have 45,70\% of the visitations, European 38,48\%, American North 5,12\%, Asian 4,12\% and Oceanic 1,03\%. The terrestrial access to Roraima Mount is only accomplished by Venezuela.
\end{abstract}

Keywords: Roraima Mount; Ecotourism; Indigenous People; National Park.

\footnotetext{
i Mestre no Programa de Pós-graduação em Ciências Florestais e Ambientais (PPGCIFA). Pesquisador no Núcleo de Ciências Humanas e Sociais (NPCHS-INPA) Etnoecologia. E-mail: betodelf@gmail.com ii Prof ${ }^{\circ}$ Dr. Programa de (PPG-CIFA-UFAM). E-mail: jeffdacruz@yahoo.com iii Prof ${ }^{\circ}$ Dr. (PPGECO-INPA). E-mail: pydaniel@inpa.gov.br
} 


\section{Introdução}

É um fato inovador se fazer turismo em área de fronteira no norte do Brasil em Parques Nacionais junto com povos indígenas. É sabido por todos que as áreas de fronteira são protegidas e monitoradas pelas Forças Armadas Brasileiras.

Por conta deste tema tão recente e complexo descreve-se aqui estudos realizados na América do Sul, na região da "Gran Sabana" na Venezuela. No Parque Nacional Canaima, setor Sul ou Oriental. As investigações foram realizadas com intuito de entender um pouco sobre as atividades que envolvem Etnias Indígenas, Unidades de Conservação e o Turismo no extremo norte do Brasil.

Este artigo tem dois objetivos: o primeiro é a análise e descrição das investigações realizadas em 2007 aos livros de visitações do Instituto Nacional de Parques venezuelanos (INPARQUES). Na comunidade indígena Pemón Taurepáng de Paraytepuy de Roraima, na Venezuela.

Durante a pesquisa de campo em 2007 foram observados os livros de visitações do Monte Roraima disponibilizados pela gerência indígena do Parque Nacional Canaima, na Venezuela. Os livros que se teve acesso na ocasião foram os dos anos de 2002 a 2003, 2005 a 2006 e 2006 a 2007. Sendo possível identificar o perfil da demanda do Monte Roraima e o número de turista ano, através deles.

No segundo objetivo foi descrito os atrativos turísticos vivenciados durante a caminhada ao topo do Monte Roraima na companhia dos índios Pemón Taurepáng na Venezuela em 2007. Estes estudos ampliam o entendimento das bases para o desenvolvimento do turismo em áreas indígenas, sobre postas aos Parques Nacionais do extremo norte do Brasil na região da tríplice fronteira.

A necessidade de vivenciar e perceber como são realizadas, operacionalizadas e administradas às atividades turísticas em Parques Nacionais junto com etnias indígenas fora do Brasil foi o que motivou o desenvolvimento deste trabalho científico. Outras facilidades para os estudos foram o acesso fácil e rápido para a Venezuela, a partir da cidade de Manaus, no estado do Amazonas no Brasil. Os transportes, equipamentos e serviços turísticos operacionalizados pela etnia indígena Pemón Taurepáng e os preços relativamente baixos se comparados à moeda brasileira na atualidade econômica.

\section{Monte Roraima - Características Gerais}

Segundo o Guia de Turismo Ecológico (1999: 59) o Monte Roraima tem a altura de 2.875 metros sendo um dos pontos mais extremos do Brasil na América do Sul com cerca de $40 \mathrm{~km} 2$.

A geologia do Monte Roraima é formada por rochas da época da "Pangea". A geomorfologia é composta por paredes de arenito, cinco subunidades e formam uma espécie de mezanino. O clima é Tropical quente e úmido com três meses secos. A temperatura varia de $24^{\circ} \mathrm{A} 26^{\circ}$ com máxima é de $38^{\circ} \mathrm{C}$. A pluviosidade varia 1500 e $1750 \mathrm{~mm}$. A altitude chega a $2.875 \mathrm{~m}$. O solo da região é de textura arenosa, pouca argila e minerais com exceção do cristal de quartzo. O Relevo é Montanhoso e escarpado com recortes de ravina. A vegetação é Floresta Ombrófila Densa Montana. Flora 50\% de endemismo e a Fauna representa a Província Zoogeográfica Amazônica (Filho, 2003).

A Savana é conceituada como uma vegetação Xeromorfa preferencialmente de clima estacional de mais ou menos seis meses por ano (Veloso et all, 1991, apud IBGE, 2006).

Em cima do Roraima encontrasse um ambiente hostil para qualquer organismo vivo, as rochas com baixa concentração de minerais e nutrientes. Algumas plantas desenvolveram especiais meios para sua dieta pegando e digerindo pequenos animais. Outras desenvolveram habilidades para evitar perder água pela evaporação da mesma maneira os animais são obrigados a sobreviver em tais ambientes com uma quantidade limitada de alimentos e condições extremas de radiação e temperatura. (Peréz e Warren, 2007).

A fauna e flora do Monte Roraima são formadas por algumas espécies como: $\mathrm{O}$ pequeno sapo de cor negra "Oreophrynella quelch" espécie endêmica encontrada também na áfrica, o grilo mergulhador- espécie endêmica que é facilmente avistado nas piscinas naturais em cima do Monte Roraima, o pássaro tico-tico, um pequeno roedor e o "quati" o maior animal encontrado no topo do Monte Roraima. Dentre a variedade das plantas, as insetívoras "Drosera roraimae" e "Helianphora".

Em 2003 foi descoberta por espeleologistas Twecos e Eslovacos no cume do Monte Roraima, a cova "Olhos de Cristal". Isso fez com que houvesse outra expedição custeada pela "Discovery Chanel" (2007). Durante esta segunda expedição foram encontradas algumas estalactites anteriormente relatadas pela expedição dos europeus.

$\mathrm{Na}$ análise biológica das amostras das estalactites o que se viu foram microorganismos "vermes" que se originaram a partir da poeira e se alimentam do cristal de quartzo abundante no Roraima. Na verdade se trata de formações de milhões de anos e que servem de base para estudos da vida em outros planetas (NASA apud 
Discovery Chanel, 2007).

\section{Monte Roraima - Aspectos Históricos}

Existe uma quantidade de informações sobre o Monte Roraima ao longo de sua descoberta, que representa um acervo diversificado e que relata os seus variados acontecimentos.

Uma destas é uma publicação de 1596 que tem como nome: "The Discoveie of The Large Rich and Beautiful Empyer of Guiana”. E para (Marrero, 1997: 06) retratam as explorações em busca do "mito" do "Eldorado nas Guianas"

Segundo Filho (2003) o primeiro homem branco a avistar o Monte Roraima foi o inglês Sir Water Raleigh que no final do século XVI, estando em busca de tesouros, embrenhou-se pelas Antilhas e cruzou a floresta Amazônica na região da Guiana. E teria chegado até a base do Monte Roraima coletando material de pesquisa suficiente para escrever obra literária "a Montanha de Cristal".

O navegador e descobridor "Water Raleigh" segundo (Branch, 1996) era favorito da rainha Elizabeth I, o qual obtinha muitos favores para o sucesso das suas campanhas exploratórias em outras terras, e a serviço da Coroa Inglesa. Em 1595 saiu das índias iniciando assim sua jornada através do rio Orinoco na América do Sul.

O explorador "Everard In Thurn" informa Marrero (1997: 120) conquistou o cume do Monte Roraima em 07 de dezembro de 1884, a novela o Mundo Perdido relata uma imaginaria expedição a selva amazônica ao norte de Manaos. Onde havia um Monte em forma tabular na fronteiras de três países Sul Americanos.

O aventureiro botânico "Everard In Thurn" ao subir no Monte Roraima relatou detalhadamente sua expedição. Estes relatos foram publicados na revista "National Geographic - Geografia Nacional" e conforme Filho (2003) inspiraram o autor "Conan Doyle", o renomado escritor de "Sherlock Homes" a escrever "The Lost Word" publicado no início do século passado.

O ator hollywoodiano "Wallce Beery" ganhou em 1932 o Oscar e em 1934 e o prêmio cinematográfico de Veneza pelo filme em preto e branco baseado num mundo perdido. Cita Marrero (1997) que isso Influenciou para que novos filmes de aventuras retratassem lugares remotos da Terra, incluindo grandes criaturas abomináveis como King Kong. Rodado em eras passadas do cinema de Hollywood nos Estados Unidos.

Dentre os primeiros exploradores do Monte Roraima existe uma presença européia predominante. $\mathrm{O}$ autor faz referência a algumas outras expedições que marca- ram presença na "Gran Sabana".

$1 \quad 1884$ e 1898 - Mcconnel e Quelch.

21900 -1905 e 1910 - Comissões de Limites.

31912 - Koch Grumberg.

41916 - Clementi.

51927 - A primeira das cinco explorações de G. H. H que trata do Museu Americano de História Natural.

Conforme Marrero (1997) as expedições científicas a Grande Savana venezuelana começaram em 1939. Quando o Ministério de fomento patrocinou a exploração geológica da região.

No Guia Turístico do estado de Roraima no Brasil, o autor Magno Souza (2006) ressalta que em 1976 o escritor venezuelano "Charles Brewer Caria" desvendou o Vale dos Cristais no Cume do Roraima. Este Explorador e fotógrafo, a quem devem boa parte do conhecimento por conta de suas publicações sobre o local, dentre elas se destacam "Sarisariñama", a Vegetação do Mundo Perdido.

No Brasil se relata algumas expedições exploratórias e demarcadoras de fronteiras: (Governo de Roraima, 2006).

a) Em 1859 o tratado de limites para navegação com o Brasil, nesse tempo havia pendências entre Venezuela e Colômbia, fato só resolvido em 1891.

b) Em 1880 comissões mistas começaram as demarcações de fronteiras.

c) 1882 e 1884 a comissão brasileira prossegui sozinha a demarcação até o Monte Roraima, sem a comissão venezuelana.

d) Em 1928 devido ao protocolo de 24 de julho, outras comissões mistas demarcaram a linha geodésica $\mathrm{Cu}$ cuí-Uá e logo em seguida a das fronteiras a partir do Monte Roraima.

e) Em 1934 as atividades foram interrompidas e foram reiniciadas em 1939 demarcando as áreas de Parima e Pacaraima.

\section{Povos Indígenas do Monte Roraima}

Os índios Pemón ocupam toda a bacia do rio Caroni. O grupo dos Taurepáng na Parte Sul da fronteira, os Arekuna na parte central na zona de Kavanayén e os Kamaroto na parte Noroeste - Zona de Kamaratá ao leste e sul da fronteira os grupos indigenas Akawayo, os Patamona e os Makuchi.

A região da Grande Savana segundo Huber e Febres (2000: 121) é um território da etnia Pemón que significa gente/pessoa. Filho (2004) diz que muito antes da criação do Parque Nacional Monte Roraima e o Parque Nacional Canaima já existiam áreas indígenas

Os autores Schubert e Huber (1989: 16) afirmam 
que os habitantes autônomos da Grande Savana são os índios Pemón, segundo o censo indígena de 1982, a população Pemón somava a quantia de 11.464 correspondentes a $8,16 \%$, do total da população indígena da Venezuela. Todos descendem do tronco lingüístico "Caribe" e ao oeste do rio "Caroni" vivem os "Ye'kuana".

Conforme Costa e Souza et al (2005: 51) a historia da aproximação com os Taurepáng com o ocidente ocorreu devido à imigração do grupo para o interior do continente devido aos avanços constantes dos empreendimentos exploratórios e coloniais levados pelos espanhóis desde 1600.

A uma tradição das guerras e enfretamentos de grupos indígenas na região do Monte Roraima. Existem crônicas que retratam que os habitantes do rio "Caroní" e "Icabarú" se matavam uns aos outros. Atualmente os índios Pemón são muitos discretos em falar destes temas.

Ao sul da "Gran Sabana" se fala com freqüência de enfreamentos das etnias Pemón Taurepáng e os Macuxí. As migrações das etnias Macuxí e Taurepáng aconteceram simultaneamente para as Savanas de Rio Branco. Os Taurepáng na conquista e consolidações dos territórios atuais lutaram durante os séculos XVI e XVII, estas guerras nem todas se ocasionavam das diferenças etno-culturais e sim pela indução de interesses de países como: Espanha, Portugal, Inglaterra e Holanda (Huber e Febres, 2007: 131).

Conforme Marrero (2007) Os índios Pemón expressam os meses por tempos, de dezembro a maio é o tempo do sol, de junho a novembro período que associam com a desova dos peixes, agosto a época dos ventos, "arranca pássaros" em setembro é a época dos "zancudos" (mosquitos). Na atualidade os jovens Pemón gostam de jogar futebol nas tardes e os turistas são bem vindos.

Os índios Taurepáng no Brasil estão situados na (TI) Terra Indígena Raposa do Sol na aldeia Bananal, tendo cerca de 176 habitantes em uma região de fronteira com a Venezuela e a Guiana (Premio Culturas Indígenas (2009). A (TI) Terra Indígena São Marcos também é habitada por uma população etnicamente diversa: Wapixana, Macuxí e os Taurepáng (socioambiental.org, 2009).

\section{Raízes Culturais}

Para Marrero (1997) o Monte Roraima representa para os índios "Pemón" venezuelanos e para os índios brasileiros "Ingaró" e "Macuxí", a casa do Deus "Macunaíma", além dos índios Pemón venezuelanos também o chamarem de mãe de todas as águas. E de "Roroima" que significa grande verde azulado.
Frei Cesário de Armallada (apud Marrero, 2006) na sua obra "Uma Festa Índia em Kamarata" expressa que todas as montanhas são casas, mundos, onde estão os espíritos.

O autor cita que a obra de José Berti Filho, "Hacia El Oeste Corre El Antabare" e "Pemonton Wanari" de Barceló Sinfontes, retrata que os índios Pemón "Arekuna" como a maior parte das tribos pré-colombianas não crê na morte natural e para explicar a sua desaparição neste mundo tem criado um símbolo, um personagem "Canaima", que os perseguia sem parar e depois vencia e matava a pessoa.

Canaima tem poli-formas adaptando-se aos locais em que vive. Canaima significa a morte que é seu eterno e implacável inimigo. O ser Canaima tem sido interpretado de várias maneiras mais só os Pemón sabem sobre o terror que gera entre eles, o poderoso que pode ser.

Durante a pesquisa de campo ao Monte Roraima em 2007, muito se ouviu falar na região sobre um ser conhecido por "Canaima", um ser que fazia emboscada para os outros índios na floresta e nos caminhos. Fumava uma erva que soprava na pessoa amaldiçoando-a, deixandoa doente, que maltrata a vítima arrancando a língua e que se transformava em animal.

Foi dito pelos índios Pemón da "Gran Sabana", que existem pedras sagradas que não devem ser tocadas pelo risco de morte. E de luzes fortes no topo dos "Tepuys" ou montanhas. Que acreditam ser ouro.

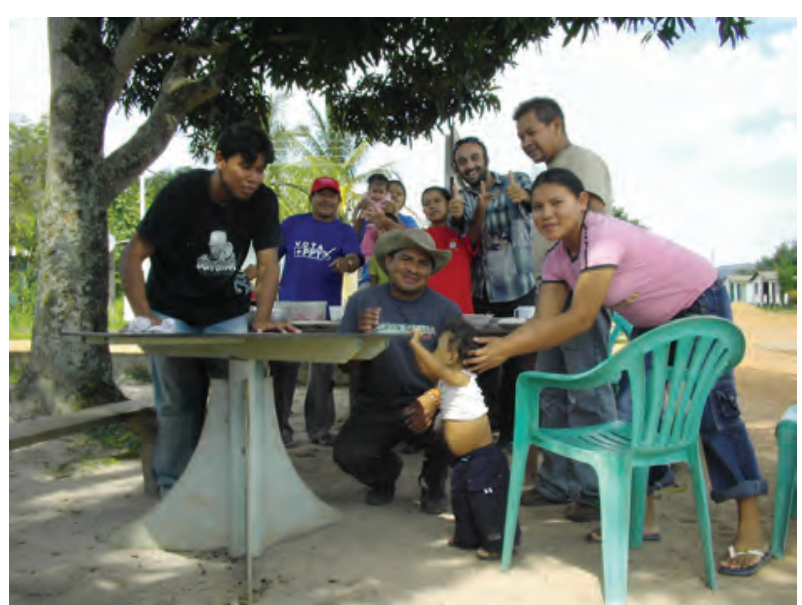

Figura 01: Família Indígena Pemón Taurepáng e Roberto Delfino -Paraytepuy de Roraima -Família Delgado. Fonte: Roberto Delfino, Pesquisa de campo, Venezuela 2007. 


\section{O Turismo de Natureza}

$\mathrm{O}$ crescimento do turismo de natureza mundial é de cerca de $10 \%$ a $30 \%$ conforme Mckercher (2002). Mais a presença humana cita Miranda (2003) é o maior fator de impacto sobre o meio ambiente. Por conseqüência do desenvolvimento do turismo de natureza pode-se dizer que o mesmo já chegou aos lugares mais inóspitos da terra.

Goidanich e Molleta (2001) descrevem que prova disso é o número de pessoas que estão se deslocando para encontrar locais com características peculiares de aventura. Exemplos são as viagens turísticas a Antártida e a Patagônia que são comumente oferecidas no mercado turístico internacional.

Conforme o decreto (Decreto Lei de $\mathrm{n}^{0} 56 / 2002$ ) o turismo de natureza é o produto turístico, composto por estabelecimentos, atividades e serviços de alojamento e animação turística e ambiental realizados em zonas integradas na rede nacional de áreas protegidas, adiante designadas por áreas protegidas.

Os autores Lage e Milone (2001) afirmam que em muitas situações as atividades turísticas impõem certos custos sociais e ambientais às regiões turísticas e aos residentes, muitas das vezes o crescimento do turismo pode provocar uma devastação nos recursos naturais e culturais dessas regiões.

Leuzinger (2002: 33-34) diz que a forma que mais se adequada a dar proteção ao ambiente natural e a de se estabelecer ordem de fluxo, nos países ricos os Parques Nacionais possuem incentivos e vantagens turísticas como: fornecimento de mapas, qualificação de guias, manutenção de rotas, hotelaria e acampamentos e manutenção de equipe de resgate.

Teixeira (2000: 13) afirma ser inconcebível a idéia de que não pode haver desenvolvimento nas localidades sem danos diretos a qualidade de vida das pessoas e dos ecossistemas. Mais o que diz a regulamentação dos Parques Nacionais Brasileiros?

\section{Parque Nacional}

$\mathrm{O}$ artigo ( $\mathrm{n}^{\circ}$ 9.985, de 2000), que regulamentou o (SNUC) Sistema Nacional de Unidades de Conservação da Natureza no Brasil, que incluiu os Parques Nacionais no grupo das Unidades de Proteção Integral e que em seu Art. 11, traz a seguinte definição.

O Parque Nacional tem como objetivo básico à preservação de ecossistemas naturais de grande relevância ecológica e beleza cênica, possibilitando a realização de pesquisas e o desenvolvimento de atividades de educação e interpretação ambiental, de recreação em con- tato com a natureza e o turismo ecológico (SNUC, 2000).

Para os autores Schubert e Huber (1989: 91) os objetivos de um Parque Nacional são a preservação, recreação, educação e investigação. Queremos realmente conservar o Parque, educar o cidadão e investigar o meio ambiente para poder tomar as medidas racionais para a sua conservação.

O Parque Nacional de "Sitka" no Alaska é um bom exemplo do turismo de natureza realizado em 43 hectares de cenários espetaculares e apresenta parcerias bem sucedidas entre as populações tradicionais e as autoridades responsáveis pelo Parque Nacional.

Segundo Wearing e Neil (2001: 136-137) neste Parque a cultura americana é central na experiência interpretativa. Precisavam ser nativos americanos para interpretar sua própria cultura; quando se romantiza a respeito de uma cultura nativa, perde-se a perspectiva de que e uma cultura em desenvolvimento, viva, e não um produto fabricado.

Os autores (S. Bowman 1998: 30-33; Wearing e Neil 2001: 137) citam que os índios guias Nortes Americanos Navarro estão vivendo a sua própria história suas famílias continuam a pastorear ovelhas e cabras nos cânions depois de 500 anos e descrevem a interação entre visitantes e as culturas nativas.

A Costa Rica é reconhecida mundialmente no que se diz respeito às praticas ecoturisticas e o turismo científico. É um país pequeno com cerca de $51.100 \mathrm{~km}$ quadrados situando-se na América Central, que recebeu mais de um milhão de turistas no ano de 2000.

A Costa Rica diz Pacheco (2003: 04 - 06) é uma espécie de Parque de diversões para os amantes da natureza e da aventura e tem uma diversidade de produtos turísticos como: a observação de aves, borboletas, serpentes, cannyoning, rafting, passeio em pontes de cordas meio a bosque nebuloso e vulcões ativos.

$\mathrm{Na}$ Espanha se encontra o Parque de Natureza "Noudar" que está situado em Barrancos, no estado de Alantejo. Este Parque tem princípios na conservação de seus territórios com estratégias de oferta local de emprego qualificado em diversas áreas, utilização de novas tecnologias em prol da interpretação ambiental. O parque produz e distribui os conteúdos das interpretações na forma de Multimídia com apoio de especialistas. As informações são difundidas por meio de um guia digital. (ARENA - Ordenamento e Gestão dos Recursos Naturais (2007).

Na gelada Patagônia Argentina. O turismo de natureza tem caráter cientifico onde é o possível vivenciar o derretimento das geleiras locais a poucos metros de distância. O derretimento acelerado do das paredes de gelo nos últimos anos tem sido tema de investigação tu- 
rística científica local. Durante o percurso turístico de barco meio aos blocos de gelo e icebergs, são discutidos temas como o aquecimento global, o derretimento das geleiras e o reflexo das conseqüências disso, a médio e longo prazo para o Planeta Terra (Rede Globo de Televisão, 2011).

\section{Material e Métodos}

\section{Área de Estudo}

O Monte Roraima é o marco divisório de três países na América do Sul: Na República Federativa do Brasil situa-se na Serra de Pacaraima no Parque Nacional do Monte Roraima. Na República Bolivariana de Venezuela localiza-se na região da "Gran Sabana" inserido no Parque Nacional Canaima, setor Oriental ou Sul. Na República Cooperativista da Guiana situa-se na zona de reclamação, área em disputa jurídica entre Venezuela e Guiana.

As localizações das fronteiras entre Venezuela, Guiana e Brasil inseridas no (Guia Philips, 1999, p 59) dizem que o ponto tríplice marca as coordenadas "Sul, $05^{\circ} 00^{\circ}$ e $05^{\circ} 16^{\prime}$ e Oeste, $60^{\circ} 00^{\prime}$ e $60^{\circ} 40^{\circ}$ ". O acesso via terrestre ao Monte Roraima, a partir da cidade de Manaus, Brasil, na América do Sul e inicia-se pela BR 174 até a cidade de Boa Vista extremo norte do Brasil.

$\mathrm{O}$ primeiro percurso para se chegar à área de estudo possui $760 \mathrm{~km}$, saindo da cidade de Manaus para Boa Vista no Estado de Roraima (Brasil) até Santa Elena de Uiarén na (Venezuela) são mais $240 \mathrm{~km}$ e de Santa Elena até a comunidade indígena de San Francisco de Yuruaní mais $69 \mathrm{~km}$. Restando apenas os últimos 22 $\mathrm{km}$ até os índios Pemón de Paraytepuy de Roraima onde se inicia a caminhada rumo ao topo do Monte Roraima (Pesquisa de campo, 2007).

Parte deste percurso realiza-se pela rodovia "Simon

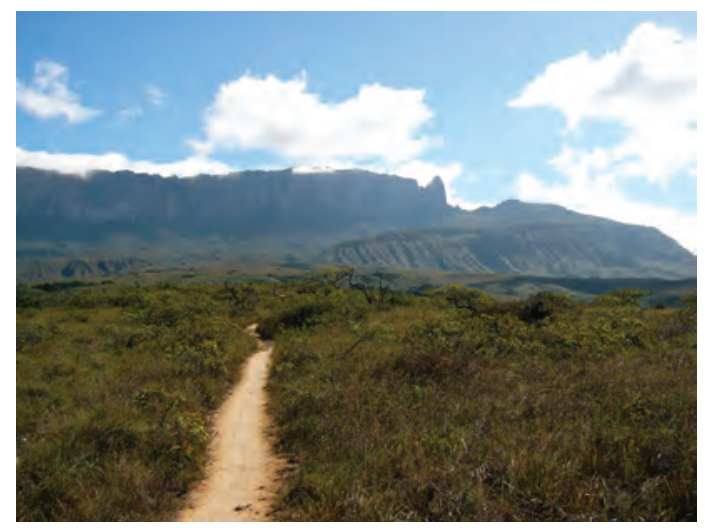

Figura 02: Monte Roraima: Venezuela, 2007. Fonte: Roberto Delfino.

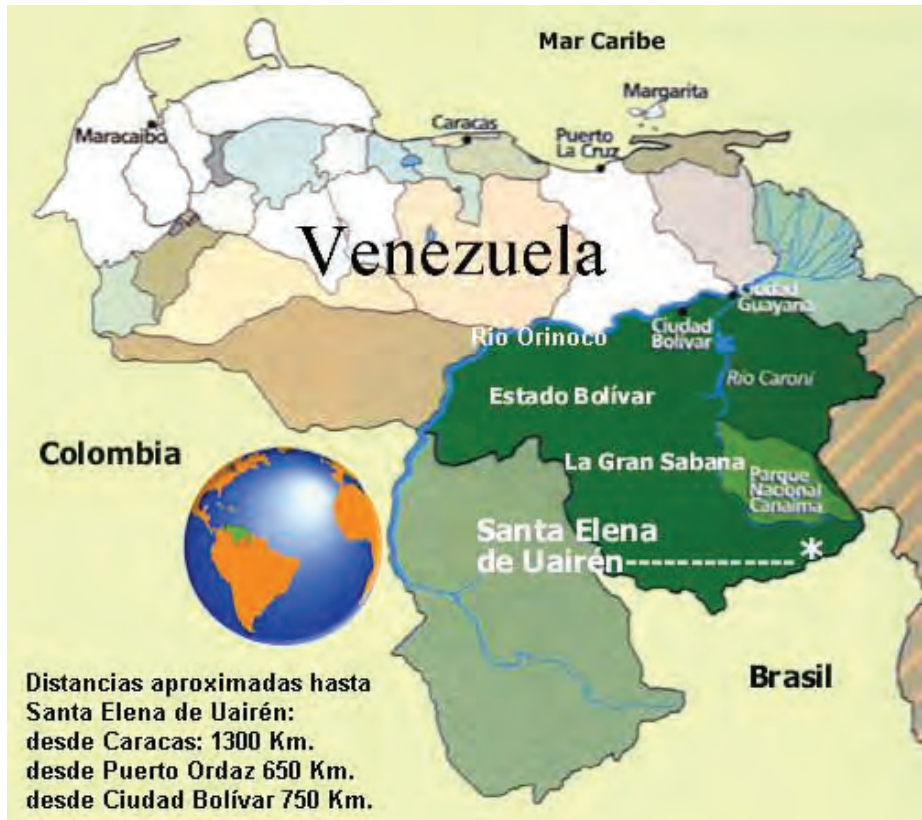

Figura 03: Mapa da localização do Parque Nacional Canaima. Fonte: La Gran Sabana.com, 2007.

Bolívar" ou "Troncal 10" a continuação da

Rodovia BR 174 do lado brasileiro. O outro percurso é realizado por meio de um ramal em estrada de piçarra e barro venezuelana.

\section{Metodologia}

A metodologia foi exploratória e visou interpretar o local visitado sem alterações dos dados e informações (Gonçalves, 2005: 57). As informações contidas no livro de visitações do Monte Roraima, na Venezuela são a base para a sustentação dos resultados propostos com $o$ artigo.

Todos os dados foram coletados em 2007 durante a pesquisa de campo na região do Monte Roraima. Na Grande Savana Venezuelana. América do Sul.

As ferramentas técnicas estatísticas, quantitativa discreta e qualitativa nominal foram utilizadas para se saber o número de turistas que visitou o Monte Roraima entre os anos de 2002 e 2003 e 2005 e 2006 e 2006 e 2007. Assim como, se saber as nacionalidades, profissões e idades dos turistas.

O critério para seleção das amostras baseo-se nos livros de visitações disponibilizados pelos índios Pemón na sede do Instituto Nacional de Parques Venezuelanos (2007). Neste mesmo período foi realizada a caminhada ao topo do Monte Roraima junto com índios Pemón Venezuelanos, sendo possível vivenciar e descrever alguns atrativos turísticos naturais e culturais da etnia Pemón no local. 


\section{Resultados e Discussão}

O mundo visita o Monte Roraima. Os dados e informações coletados durante a pesquisa de campo em 2007, na base do (INPARQUES) Venezuela, destacam isso.

\section{Estimativas Numéricas e Caracteństicas dos Visitan- tes do Monte Roraima.}

O crescimento da demanda turística diz Ruschmann (1997: 15) é conseqüência da oferta do turismo, e de suas facilidades para todos os lugares estando acessível aos viajantes ávidos por novos destinos em lugares com recursos naturais e culturais consideráveis.

Para se estimar as visitações turísticas ao Monte Roraima foi realizada a observação e contagem numérica uma a uma das assinaturas/linhas do livro de visitações dos turistas do Monte Roraima. Nos anos de 2002 a 2003, 2005 a 2006 e 2006 a 2007.

No quadro abaixo foi multiplicado o número de páginas assinadas no livro pela média das assinaturas por página, que variam entre 23, 24 e 25 linhas.

\begin{tabular}{|c|c|c|c|}
\hline Março de 2002 & 19 pág. & 23 assinaturas & 437 pessoas \\
\hline Abril & 05 pág. & 23 assinaturas. & 115 pessoas \\
\hline Maio & 06 pág. & 23 assinaturas & 138 pessoas \\
\hline Junho & 07 pág. & 23 assinaturas & 161 pessoas \\
\hline Julho & 16 pág. & 23 assinaturas & 368 pessoas \\
\hline Agosto & 26 pág. & 23 assinaturas & 598 pessoas \\
\hline Setembro & 08 pág. & 25 assinaturas & 200 pessoas \\
\hline Outubro & 08 pág. & 24 assinaturas & 192 pessoas \\
\hline Novembro & 11 pág. & 25 assinaturas & 275 pessoas \\
\hline Dezembro & 11 pág. & 25 assinaturas & 270 pessoas \\
\hline Janeiro de 2003 & 03 pág. & 25 assinaturas & 075 pessoas \\
\hline Total & 120 pág. & 2.819 assinaturas & 2.819 pessoas \\
\hline
\end{tabular}

Quadro 01: Número de turistas ao Monte Roraima ano separado por mês, de março de 2002 a janeiro de 2003. Fonte: Pesquisa de campo, fevereiro de 2007, livro do INPARQUES. Paraytepuy de Roraima, Venezuela.

Quadro 01: Número de turistas ao Monte Roraima ano separado por mês, de março de 2002 a janeiro de 2003. Fonte: Pesquisa de campo, fevereiro de 2007, livro do INPARQUES. Paraytepuy de Roraima, Venezuela.

Neste caso foram selecionadas em media vinte e três paginas/mês, de março de 2002 a janeiro de 2003 que correspondem uma média de 23 visitantes por página. Os números encontrados permitem uma pequena margem de erro que está no fato dos guias também assinarem o livro sendo incluídos como visitantes muitas das vezes. Neste período os meses mais visitados foram março, julho e agosto de 2003.

De setembro 2005 a setembro de 2006 foi utilizado o mesmo processo na coleta dos dados sendo registrada a presença de 3.298 pessoas no Monte Roraima. Estes indicadores correspondem a 97 páginas do livro de visitações do Instituto Nacional de Parques Venezuelanos no período.

Entre vinte e oito de julho de 2006 a vinte de fevereiro de 2007, os visitantes já passavam de 2.244 pessoas, correspondentes às 66 páginas do livro no período, o que caracteriza um aumento considerável da sua demanda turística.

Os indicadores são parecidos com os do gestor indígena do Parque Nacional Canaima in comunicação pessoal (2007) que relata a estimativa de 3.300 pessoas. Filho (2004) cita a presença de 3.000 turistas. O escritor Roberto Marrero é um dos pioneiros nas atividades turísticas ao Monte Roraima. Marrero In comunicação pessoal 2007 descreve o crescimento de $500 \%$ nas visitações ao Monte Roraima nos últimos anos.

Segue abaixo o quadro do crescimento das visitações turísticas ao Monte Roraima nos anos estudados.

Os anos de 2002 a 2003 se comparados ao de 2005 a 2006, verifica-se um aumento de quase 500 pessoas. Nos sete meses entre Julho 2006 à Fevereiro de 2007 os indicadores chegavam a 2.200 pessoas. Mostrando um aumento continuo no crescimento das visitações nos últimos anos e que deverá ultrapassar os 3.298 turistas expressos entre os anos de 2005 a 2006.

No que se refere às nacionalidades a amostragem foi delimitada a uma linha ou turista por página dos livros de registro do Instituto Nacional de Parques Nacionais

\begin{tabular}{|c|c|}
\hline Anos estudados & Total de turistas \\
\hline $2002-2003$ & 2.819 \\
\hline $2005-2006$ & 3.298 \\
\hline Julho 2006 a Fevereiro de 2007 & 2.224 \\
\hline
\end{tabular}

Quadro 02: Crescimento das visitações ao Monte Roraima. Fonte: Pesquisa de campo, fevereiro de 2007, livro do INPARQUES. Paraytepuy de Roraima, Venezuela. 


\begin{tabular}{|c|c|c|}
\hline Origem dos Turistas & № por continentes & Soma por continente em (\%) \\
\hline Sul Americano & 67 Turistas & $55,83 \%$ \\
\hline Europeu & 44 Turistas & $36,66 \%$ \\
\hline Norte Americano & 05 Turistas & $4,16 \%$ \\
\hline Oceânico & 03 Turistas & $2,5 \%$ \\
\hline Asiático & 01 Turistas & $0.8 \%$ \\
\hline Total 120 linhas/amostra & 120 turistas & $100 \%$ \\
\hline
\end{tabular}

Tabela 01: Turistas do Monte Roraima separados por continente de março de 2002 a janeiro de 2003. Fonte: Pesquisa de campo, fevereiro de 2007, livro do INPARQUES. Paraytepuy de Roraima, Venezuela.

\begin{tabular}{|c|c|c|}
\hline Origem dos Turistas & № por continentes & Soma por continente em (\%) \\
\hline Sul Americano & 133 & $45,70 \%$ \\
\hline Europeu & 112 & $38,48 \%$ \\
\hline Norte Americano & 17 & $5,12 \%$ \\
\hline Oceânico & 03 & $1,03 \%$ \\
\hline Asiáticos & 12 & $4,12 \%$ \\
\hline Outros (ilegíveis) & 09 & $3,09 \%$ \\
\hline Sem informação & 05 & $1,71 \%$ \\
\hline Total 291 - amostra & 291 turistas & $100 \%$ \\
\hline
\end{tabular}

Tabela 02: Origem dos turistas do Monte Roraima separados por continente de setembro de 2005 a setembro de 2006. Fonte: Pesquisa de campo, fevereiro de 2007, livro do INPARQUES. Paraytepuy de Roraima, Venezuela.

\begin{tabular}{|c|c|c|}
\hline Turistas & № Turistas por profissão & Total de turistas em (\%) \\
\hline Estudantes & 58 & $41 \%$ \\
\hline Engenheiro & 19 & $13 \%$ \\
\hline Professor & 21 & $15 \%$ \\
\hline Guias & 14 & $10 \%$ \\
\hline Sem informação & 14 & $04 \%$ \\
\hline Outros & 06 & $03 \%$ \\
\hline Médicos & 05 & $03 \%$ \\
\hline Outras profissões & 05 & $01 \%$ \\
\hline Carregador & 01 & $100 \%$ \\
\hline Total 143 - amostra & 143 & 06 \\
\hline
\end{tabular}

Tabela 03: Profissões dos turistas do Monte Roraima de 01/09/2005 a 22/09/2006. Fonte: Pesquisa de campo, fevereiro de 2007, livro do INPARQUES. Paraytepuy de Roraima, Venezuela.
Venezuelanos. Ou seja, cada linha/pessoa foi selecionada, contada e separada por continentes. Nas duas tabelas que seguem o continente Americano foi separado em Norte e Sul.

Os números da tabela 01 demonstram que os povos da América do Sul representam $55,83 \%$ das visitações, seguidos pelos Europeus $36,66 \%$ presentes desde o século passado no Monte Roraima.

Nos anos de 2005 a 2006 (Tabela 02), os povos da América do Sul continuam em primeiro lugar mais baixam a sua media de $55,83 \%$ para $45,70 \%$. Os Europeus elevaram sua media nas visitas de 36,66 para $38,48 \%$. E os Norte Americanos sobem de 4,16 para $5,16 \%$.

No que se refere às profissões dos visitantes e sua idade, a amostragem foi delimitada a uma assinatura/pessoa de cada página assinada do livro de registro do Monte Roraima. Os estudantes encabeçam a lista, mais principalmente devido aos estudantes da Venezuela. Os segundo são os engenheiros com $13 \%$ e os professores com $15 \%$. Os guias locais expressão cerca de $10 \%$ das visitações no período acima.

Neste quadro (Tabela 04), a variedade de profissões encontradas no período continua diversa. Os estudantes generalizados somam $30,45 \%$ das visitações, e continuando no topo da lista. Seguidos pelos guias com 17,27\% e engenheiros com $11,67 \%$. Os professores aparecem em quarto lugar mantendo-se entre os que mais visitam.

As idades dos turistas (Tabela 05) que mais visitam o Monte Roraima de 2005 e 2006 são da faixa etária de 21 a 30 anos com $39 \%$ que é a grande maioria, de 31 a 40 anos, com $19 \%$ e 41 a 50 com $15 \%$. O aventureiro mais velho identificado no livro de visitações no período tinha 73 anos, e o mais novo, 09 de idade.

\section{Caminhada Turística ao Topo do Monte Roraima.}

Saindo de Manaus no sentido à Boa Vista chegasse a Santa Elena de Uairén na Venezuela, na América do Sul cidade que faz fronteira com o Brasil na Serra de Pacaraima. Centrada na Grande Savana Setor Sul ou 


\begin{tabular}{|c|c|c|}
\hline Profissão dos turistas & № Turistas por profissão & Total de turistas em (\%) \\
\hline Estudantes generalizados & 60 & $30,45 \%$ \\
\hline Guias & 34 & $17,25 \%$ \\
\hline Engenheiro & 23 & $11,67 \%$ \\
\hline Professor & 11 & $5,58 \%$ \\
\hline Carregadores & 07 & $3,55 \%$ \\
\hline Economista & 05 & $2,53 \%$ \\
\hline Médico & 05 & $2,53 \%$ \\
\hline Gerente & 04 & $2,03 \%$ \\
\hline Sem informação & 47 & $23,85 \%$ \\
\hline Outros & 01 & $00,05 \%$ \\
\hline Total 197 - amostra & 197 & $100 \%$ \\
\hline
\end{tabular}

gatória a parada para a observação do passaporte com inspeção e bagagem, na ida e na volta, portanto não se exalte ou ache anormal de forma alguma, pois é o procedimento diário e normal para os militares Venezuelanos em área de fronteira.

San Francisco de Yuruaní fica logo depois de Santa Elena de Uairén e está situada em numa reserva indígena no Parque Nacional Canaima. Conhecido por seus montes, rios, florestas, cachoeiras, piscinas naturais com cristais e ecossistemas endêmicos.

Os índios Pemón Taurepáng têm lá um dos seus maiores assentamentos. A infra-estrutura básica e de apoio turístico são satisfatórias com a presença de

Tabela 04: Profissões dos visitantes do Monte Roraima no período de 28/07/2006 á 22/02/2007. Dados inseridos nas 77 páginas do livro do (INPARQUES) no período. Fonte: Pesquisa de campo, fevereiro de 2007, livro do INPARQUES. Paraytepuy de Roraima, Venezuela.

\begin{tabular}{|c|c|}
\hline Idades & $\%$ \\
\hline 10 à 20 anos & $10 \%$ \\
\hline 21 à 30 anos & $39 \%$ \\
\hline 31 à 40 anos & $19 \%$ \\
\hline 41 à 50 anos & $15 \%$ \\
\hline 51 á 60 anos & $06 \%$ \\
\hline s/informação & $11 \%$ \\
Amostra 291 linhas & \\
\hline
\end{tabular}

Tabela 05: Idades dos Turistas do Monte Roraima no período de 01/09/2005 a 22/09/2006. Fonte: Pesquisa de campo, fevereiro de 2007, livro do INPARQUES. Paraytepuy de Roraima, Venezuela.

Oriental.

Em Santa Elena de Uairén é possível encontrar infra-estrutura básica e turística satisfatória, além de comércio desenvolvido (Zona Franca). Próximo a Santa Elena funcionam acampamentos turísticos que oferecem comida e hospedagem na Grande Savana venezuelana.

Nesta localidade foi experimentada a "arepa", comida típica local a base de massa de milho, acompanhada de queijo, presunto, carne, porco salsicha ou frango. E também a deliciosa bebida "maltín" da cervejaria polar venezuelana.

Vale ressaltar que no percurso para o Roraima na barreira do exército venezuelano em San Ignácio é obri- restaurantes, pousadas, banheiros públicos e policiamento indígena.

O artesanato local é desenvolvido existindo uma variedade de tendas com trabalhos que retratam a cultura material local. Os trabalhos em pedra "jaspe e a pedra caulim" sintetizam os ensinamentos deixados pelos povos mais velhos. É possível nesta localidade se contratar serviços de guias e carregadores para os acampamentos da Gran Sabana incluindo o "Trekking" ao Monte Roraima.

Em carro com tração 4x4, a cerca de uma hora se chega à comunidade indígena de Paraytepuy de Roraima na Venezuela o acesso é feito através de uma estrada de barro e piçarra. Os Montes Kukenan e Roraima fazem parte da cadeia de montanhas locais.

O Instituto Nacional de Parques venezuelanos (INPARQUES) realiza o controle e o monitoramento dos visitantes ao Monte Roraima em Paraytepuy de Roraima. Esta comunidade atualmente conta com uma igreja, pousada e restaurante.

A partir de Paraytepuy de Roraima inicia-se a caminhada ao cume do Monte em seus primeiros $13 \mathrm{~km}$, cerca de seis horas de caminhada na Grande Savana subindo e descendo colinas passando por pequenas florestas "ombrófilas" (orquídeas, bromélias e samambaias) e rios como o "Tekparu" e o rio "Kukenan".

Durante esta caminhada foi observada a importância de se montar acampamento distante das margens dos rios por motivo de segurança. Os rios podem subir rapidamente em volume de água. É importante que ao passar os rios, se o mesmo estiver cheio, utilizar meias, pois aderem melhor às pedras escorregadias evitando acidentes.

Logo ao deixar os dois rios inicia-se uma caminhada 


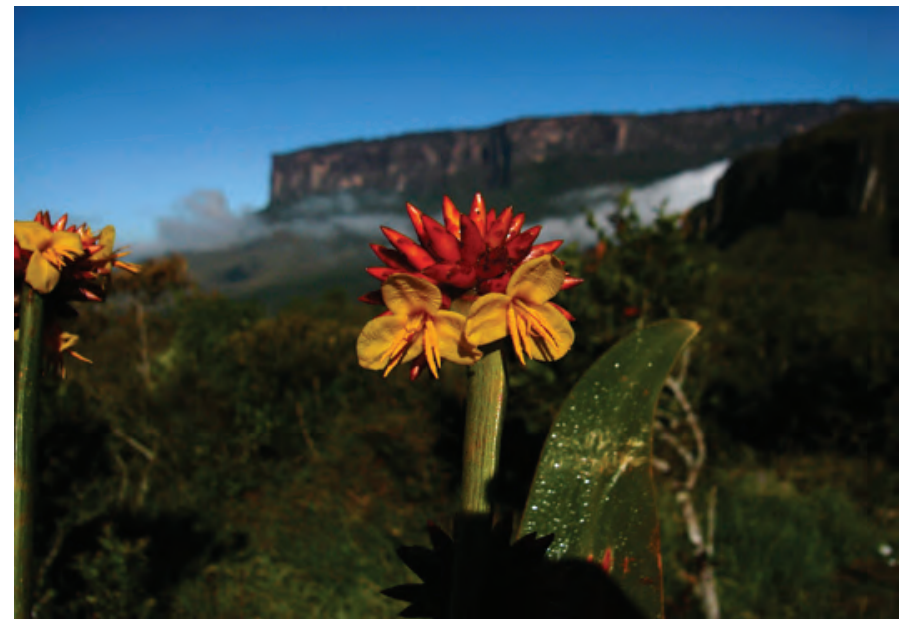

Figura 04: RAPATACEAE - parente da espécie africana "Estegolepsy". Fonte: Jefferson da Cruz e Roberto Delfino. Pesquisa de campo, 2007.

de $9 \mathrm{~km}$, cerca de quatro horas até o pé do monumental Monte, que passa pelo acampamento na base no sopé, nesta caminhada é possível ver a espécie vegetal resistente ao fogo, a Bulbostylis paradoxa (CYPERACEAE) e a (RAPATEACEAE) parente da Africana "Estegolepsy".

De lá ao cume do Monte Roraima são mais de 2,5 $\mathrm{km}$, sendo necessário mais esforço físico, este percurso tem cerca de 2 horas e meia em uma mata mais fechada e alagada chegando-se ao começo da rampa de uns 800 metros de extensão e uma inclinação de $45^{\circ}$ graus.

Neste ponto se ver cachoeiras bem ao pé do Monte chamadas de "o passo das lágrimas" onde se deve ter cuidado devido ao grau de dificuldade deste trecho.

Logo após a ascensão percebesse a pedra da tartaruga, que dá as boas vindas aos recém chegados.

Indo direto para as cavernas/hotéis esculpidas pela natureza através da ação contínua dos ventos e da chuva, dando origem às formações geomorfológicas de ravina.

Os hotéis de pedra como são chamados estas cavernas são apropriadas para montar acampamento durante a estadia no topo do Roraima. O Início da caminhada no cume é logo ao amanhecer. De lá é possível sentir a força mística dos dois montes. O Roraima se tem uma paisagem privilegiada do Monte "Kukenán" seu irmão e vizinho. O Marco Tríplice que faz fronteira do Brasil, Venezuela e Guiana é percebido depois de umas 4 horas de caminhada.

Dentre os atrativos encontrados no topo do Roraima encontram-se: o Vale dos Cristais, o "Fozo", a "Ventana" as Piscinas Naturais e a Pedra "Maverick" de onde se tem uma linda visão da Grande Savana.

Neste percurso observam-se plantas e animais en-

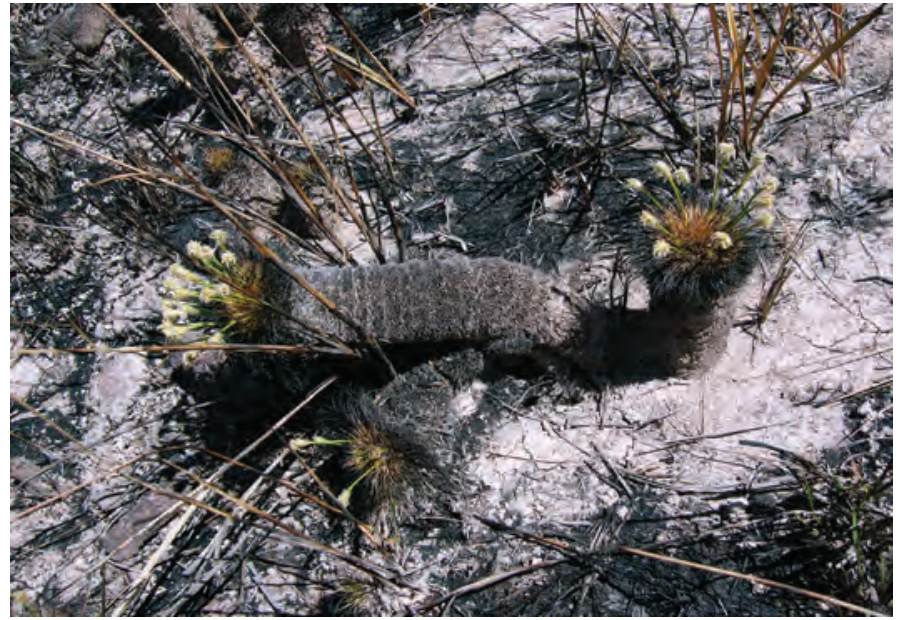

Figura 05: Bulbostyles paradoxa. Espécie resistente ao fogo. Fonte: Jefferson da Cruz e Roberto Delfino. Pesquisa de campo, 2007

dêmicos e formações geomorfológicas esculpidas meio as paisagens inimagináveis. No sentindo da segurança foi observado que as orientações dos guias devem ser respeitadas, pois os mesmos sabem por intermédio do tempo os melhores lugares a serem visitados com segurança.

Dentre as formações rochosas encontradas no cume do Monte Roraima estão: O elefante, os lobos se beijando, o macaco comendo sorvete de casquinha, os labirintos, os soldados em formação, a piscina presidencial, o templo indígena, o falo, a mulher grávida, a pedra da tartaruga, o osso, o canguru, o anfiteatro, a cadeira presidencial, o cachorro com a nádega levantada, a Plaza Bolívar, o dragão, dentre outras (Marrero, 2006).

A maior elevação no Monte Roraima a pedra "Maverick" tem a forma de um veículo Ford com o mesmo nome. As piscinas naturais com fundo de cristais no topo do Roraima são chamadas de "jacuzi" e representaram a captação de boa energia mística e melhores sentimentos astrais.

\section{Considerações finais}

Na visita técnica em 2007 ao Monte Roraima no Parque Nacional Canaima (Venezuela-América do Sul) ficou comprovado que os índios da etnia Pemón praticam um turismo de natureza que associa nos seus serviços as suas historias e mitos passados pelos mais velhos. Ninguém melhor que eles mesmos para proporcionarem satisfação e segurança à demanda que os visita.

$\mathrm{Na}$ Republica Bolivariana de Venezuela. Os índios Pemón foram capacitados pelo Governo Federal para realizam hospedagem, serviços de transportes, guias/ 
carregadores de bagagem. Sendo que, os gestores e os prestadores de serviço do Parque Nacional Canaima são todos indígenas, até mesmo o serviço de policiamento local.

O periódico estudou a atividade turística indígena na região da tríplice fronteira do Brasil, Venezuela e Guiana na América do Sul. Neste período foi identificado o número de turistas nos últimos anos, assim como o perfil da demanda turística do Monte Roraima.

O Monte Roraima tem expressividade como atrativo turístico mundial não só pelo número de visitantes expressos nos livros, que são cerca de três mil e quinhentas pessoas ao ano. Mais também pela diversidade de turistas de vários países e que envolvem todos os continentes terrestres.

Os indicadores são relevantes para futuros estudos e comparações no Brasil. Que deverá desenvolver muito em breve, o turismo de natureza no Parque Nacional Monte Roraima na companhia dos índios da etnia Taurepáng, parentes dos índios Pemón Taurepáng venezuelanos.

Mais dois fatos relevantes são o desenvolvimento do etnoturismo em 2011 na região do Alto Solimões na fronteira do Brasil, Perú e Colômbia. Como também o baixo número de periódicos voltados para as experimentações científicas de pesquisadores ativos ao entendimento das relações que envolvem Parques Nacionais, Povos Indígenas e o Turismo.

Atualmente tornou-se necessário o entendimento destas relações entre os gestores dos Parques Nacionais, as etnias indígenas e o turismo no Brasil. As etnias que vivem no extremo norte do país desejam desenvolver atividades turísticas em suas terras sobrepostas ao Parque Nacional Monte Roraima. Dentre elas as etnias Taurepáng, Macuxi e Wapixana, Ingaricó e Patamona.

Os Parques Nacionais brasileiros do extremo norte encontram-se fechados até os dias atuais e não contribuem para melhoria efetiva da saúde e nem para a qualidade de vida das populações indígenas que vivem no extremo norte do Brasil. Este fato inibe ao cidadão brasileiro e outros visitantes a conhecerem as culturas indígenas e os territórios extremos do Brasil.

Ao contrário do Parque Nacional Canaima, na Venezuela que está aberto aos visitantes contribuindo efetivamente para desenvolvimento sócio econômico dos povos indígenas venezuelanos.

Mais a presença do turista de natureza, diz Leuzinger (2002: 32) deve garantir o máximo de proteção ambiental com um mínimo de proibição, sendo que o ponto de equilíbrio deve ter determinação técnica e conhecimento da capacidade de suporte do bioma.

Na verdade será possível desenvolver um turismo de natureza no extremo norte do Brasil que viabilize a disseminação da cultura da conservação da natureza assim como o desenvolvimento econômico e a saúde local?

\section{Agradecimentos}

Ao Sr. Deus todo poderoso e ao povo indígena Pemón Taurepáng de San Francisco de Yuruaní e Paraytepuy de Roraima, na Venezuela. Particularmente a família indígena Delgado.

\section{Referencias citadas}

Branch, Hilary.

1996. Guide to Venezuela. Alemanha: Globe.

Costa, Souza.

2005. et all Savanas de Roraima: Etnoecologia, Biodiversidade e Potencialidades. Agrissilvipastoris. Roraima: Boa Vista Ltda, FEMACT. 202pp.

Discovery Chanel.

2007. Roraima o Mundo Perdido. TV a cabo - Net Combo - Manaus.

Decreto Lei de $n^{0}$ 56/2002.

2002. Brasília, Distrito federal.

Filho, Dias.

2004. Guia do Parque Nacional do Monte Roraima. Estado de Roraima - Instituto Brasileiro do Meio Ambiente e dos Recursos Naturais (IBAMA).

Filho, Dias.

2003. Site do Parque Nacional do Monte Roraima Brasil. Instituto brasileiro do Meio Ambiente e dos Recursos Naturais (IBAMA) Disponível: http://www. ibama.gov.br/siucweb/mostraUc.php? seqUc $=59$. Acessado 05/05/2007.

Gonçalves, Hortência.

2005. Manual de Metodologia da Pesquisa Cientifica.

São Paulo: Avercamp. 142pp.

Goidanich, Karin; Moleta, Vãnia.

2001. Turismo Esportivo. $3^{\circ}$ edição. Porto Alegre. Sebrae. $64 \mathrm{pp}$

Guias Philips.

1999. Parques Nacionais Brasil: Guia de turismo ecológico - São Paulo: Empresa das Artes - Publifolha. $384 p p$.

Gelas, Lage; Césár, Milone.

2001. A Economia do Turismo. São Paulo: Atlas. 227pp. Guia Ecológico Philips.

1999. São Paulo: Empresa das Artes, Projetos e Edições Artísticas Ltda. 382pp.

Governo do Estado de Roraima.

2006. Disponível portal@cti.rr.gov.br, Acessado, 2007. 
Huber, Otto; Febres, Gonzalo.

2000. Guia Ecológica de La Gran Sabana. Caracas: Ecografh Proyetos y Ediciones. 188pp.

INPARQUES. Instituto Nacional de Parques Venezuelanos.

2007. Livro de controle de visitantes do Monte Roraima. Paraytepuy de Roraima. Venezuela.

Leuzinger, Cláudio.

2002. Ecoturismo em Parques Nacionais. Brasília: Ambiental. 150pp.

Marrero, Roberto.

1997. Guia de La Gran Sabana. Caracas: Totmann.

Marrero, Roberto.

2006. Guia Turística de la Gran Sabana, 3 ed. Caracas: Precotur, C.A. 129pp.

Marrero, Roberto.

2007. In comunicação pessoal.

Mckercher, Bob.

2002. Turismo de Natureza, Planejamento e Sustentabilidade. São Paulo: Contexto. 303pp.

Miranda, Evaristo.

2003. Disponível: likhttp//www.eco.org.br. Acessado 04/08/2003.

Parque Noudar.

2007. ARENA - Ordenamento e Gestão dos Recursos Naturais. Disponível: parquenoudar.com Acessado 16/04/2007.

Pacheco, Leila Solano.

2003. Costa Rica: Uma Experiência Inovadora de Manejo Ambiental.

Peréz, Emílio e Warren Adriam.

2007. Tepuys de Venezuela: Monte Roraima. Embaixada Britânica Caracas, Venezuela.

Premio Culturas Indígenas.

2009. Disponível: socioambiental.org Acessado 30/03/ 2009.

Rushman, Doris.

1997. Turismo e Planejamento Sustentável: A proteção do Meio Ambiente. São Paulo: Papirus. 199pp.

Rede Globo de Televisão.

2011. Turismo Científico na Patagônia. Programa Fantástico.Acessado 02/01/2011.

Schubert, Carlos e Huber, Otto.

1989. La Gran Sabana Panoramica de Una Región. Caracas: Cadernos Lagoven. 107pp.

Souza, Magno.

2006. Guia Turístico. Estado de Roraima. Místico, exótico e inexplorado. Boa Vista - Roraima.

SNUC.

2000. Sistema Nacional de Unidades de Conservação. Brasília, DF, 2000.
S. Bowman.

1998. Iin "Partnership" National Park, jan/fev. p. 30-33.

Teixeira, Alessandra.

2000. Turismo Sustentável Mito ou Realidade. Minas Gerais.

Veloso, et all.

1992. Capítulo: Regiões Fitoecológicas e Áreas de Vegetação. São Paulo: IBGE.

Wearing, Stephen; Neil, Jonh.

2001. Ecoturismo: impactos, potencialidades e possibilidades. Manole SP. 256pp.

Recibido:

$15 / 07 / 10$

Reenviado:

$01 / 02 / 11$

Aceptado:

$10 / 02 / 11$

Sometido a evaluación por pares anónimos 